\title{
PENGUATAN KEMAMPUAN KOMUNIKASI DAN PEMBELAJARAN GURU TKIT DAN SDIT AR-RAHMAN I SIMPANG PEUT KABUPATEN NAGAN RAYA
}

\author{
Jamal Mildad $^{1}$, Yoyon Safrianto ${ }^{2}$, Rollis Juliasnyah ${ }^{3}$ \\ ${ }^{1)}$ Program Studi Ilmu Komunikasi, Fakultas FISIPOL, Fakultas Ekonomi, Universitas Teuku Umar \\ ${ }^{2)}$ Program Studi Ekonomi Pembangunan, Fakultas Ekonomi, Universitas Teuku Umar \\ ,3) Program Studi Ekonomi Pembangunan, Fakultas Ekonomi, Universitas Teuku Umar \\ e-mail: jamalmildad@utu.ac.id, yoyonsafrianto@utu.ac.id, rollisjuliansyah@utu.ac.id
}

\begin{abstract}
Abstrak
Hakikat Komunikasi adalah suatu proses sosial antar manusia, terjadi interaksi individu dengan lingkungannya akhirnya menyebabkan perubahan perilaku tidak paham menjadi paham. Guru waktu bersamaan melakukan komunikasi dengan anak didik, penukaran informasi. Komunikasi terjadi jika penyampai informasi, mengerti bentuk dan pola komunikasi yang baik. Komunikasi keterampilan mengajar guna memenuhi capaian dari pembelajaran. Kegiatan pengabdian pada SDIT dan Taman Kanak Islam Terpadu (TKIT) Ar-Rahman I Nagan Raya terletak di Lorong Cot Ganti Desa Simpang Peut Kecamatan Kuala Kabupaten Nagan Raya berdiri sejak tahun 2011. Jumlah lulusan TKIT 210 anak. Sekarang ini sebanyak 92, terdiri dari 54 murid laki-laki dan 38 anak murid perempuan. Dalam proses kegiatan belajar mengajar (KBM) di jalankan oleh sejumlah Guru sebanyak delapan orang dan satu orang kepala sekolah. Kesembilannya terdiri dari Eliza, S.Hum. selaku kepala sekolah, beserta dewan guru yang terdiri dari Sandi Herawati, A.MK, Rahmawati, A.Ma, Nursawida, S.Pd. I, Siti Aisyah, S. KM, Nurmayani, Era Diana,S. KM, Yulia Citra dan Anita serta Eka Yuni Kartika. Kelas A anak didik berjumlah 40 orang dan kelas B berjumlah 41 orang anak didik, komunikasi pendidikan dalam mentransfer ilmu kepada anaka didik melalui komunikasi efektif di TKIT dan SDIT Ar-Rahman I Nagan Raya.
\end{abstract}

Kata kunci: Penguatan Kemampuan Komunikasi, Pembelajaran Guru TKIT SDIT, Ar-Rahman I Simpang Peut Nagan Raya

\begin{abstract}
The essence of communication is a social process between humans, where individual interactions occur with their environment, eventually causing changes in behavior that do not understand. At the same time the teacher communicates with students, exchanges information. Communication occurs when the information provider understands the forms and patterns of good communication. Communication teaching skills to meet the learning outcomes. Community service activities at SDIT and Integrated Islamic Kindergarten (TKIT) Ar-Rahman I Nagan Raya are located in Lorong Cot Switch Village, Simpang Peut Village, Kuala District, Nagan Raya District, established in 2011. The number of TKIT graduates is 210 children. Currently there are 92, consisting of 54 boys and 38 girls. In the process of teaching and learning activities (KBM) it is carried out by a number of teachers as many as eight people and one school principal. The nine consist of Eliza, S.Hum. as the head of the school, along with the teacher board consisting of Sandi Herawati, A.MK, Rahmawati, A.Ma, Nursawida, S.Pd. I, Siti Aisyah, S. KM, Nurmayani, Era Diana, S. KM, Yulia Citra and Anita and Eka Yuni Kartika. Class A students totaled 40 students and class B totaled 41 students, educational communication in transferring knowledge to students through effective communication at TKIT and SDIT Ar-Rahman I Nagan Raya.
\end{abstract}

Keywords: Strengthening of Communication Skills, Learning Teachers TKIT SDIT, Ar-Rahman I Simpang Peut Nagan Raya 


\section{PENDAHULUAN}

Komunikasi pada hakekatnya adalah suatu proses sosial, yaitu sesuatu yang berlangsung atau berjalan antar manusia. Sebagai proses sosial, maka dalam komunikasi terjadi interaksi individu dengan lingkungannya. Inilah yang akhirnya menyebabkan proses perubahan perilaku dari tidak tahu menjadi tahu, dari tidak paham menjadi paham dan dari yang sebelumnya tidak mengacuhkan situasi masa depan menjadi berantusias sekali akan harapan-harapan positif pada masa yang akan datang. Demikian juga seorang guru sedang mengajar dalam waktu bersamaan melakukan komunikasi dengan anak didik artinya sedang melakukan penukaran informasi. Komunikasi tersebut akan berlangsung dengan baik jika penyampai informasi seorang guru memahami bentuk dan pola komunikasi yang baik. Komunikasi bagi guru merupakan keterampilan, yang harus dimiliki guna memenuhi capaian dari pembelajaran. Kemampuan komunikasi merupakan hal yang sangat diperlukan bagi guru dimana proses penyampaian ilmu tercapai sesuai dengan tujuan pendidikan tersebut. Komunikasi merupakan salah satu unsur penting dalam berinteraksi, baik secara verbal maupun nonverbal, tertulis maupun tidak tertulis. Dengan komunikasi yang baik, interaksi yang terjadi semakin lancar dan dapat membangun hubungan yang baik. Hubungan baik antara guru sesama guru dan anak akan terjalin melalui pola dan komunikasi yang baik. Komunikasi yang baik adalah harapan semua orang yang hidup di dunia ini tanpa terkecuali.

Public speaking merupakan bagian dari retorika komunikasi, atau oral commucation. tujuan retorika adalah persuasi yaitu keyakinan pendengar terhadap kebenaran gagasan hal yang dibicarakan pembicara. tujuan retorika membina saling pengertian yang mengembangkan kerja sama dalam menumbuhkan kedamaian dalam kehidupan, pemahaman yang sama melalui kegiatan bertutur, sehingga penutur (komunikator) dengan pemahaman retorika yang baik akan memahami masalah kejiwaan manusia pada umumnya dan kejiwaan penanggap tutur (komunikan/audien) yang akan dan sedang dihadapi, membimbing penutur/komunikator menemukan ulasan yang baik, dan membimbing penutur mempertahankan diri serta mempertahankan kebenaran dengan alasan yang masuk akal.

Katherine Miller ada beberapa persamaan konseptualisasi komunikasi, pertama Komunikasi adalah sebuah proses, yang meliputi aktifitas yang berkelanjutan (continuous), kompleks, dan tidak dapat berdiri sendiri. Pada awalnya proses komunikasi hanya berjalan secara linear dari komunikator pada komunikan (teori SMCR: SourceMessage-Channel-Receirver). Lalu muncul sebuah konsep yang dikeluarkan oleh Laswell yang menambahkan unsur "feedback" dari komunikan ke dalam proses komunikasi. Persamaan kedua adalah komunikasi merupakan proses transaksional dan sangat kompleks. Dalam konsep ini dijelaskan pula pentingnya koneksi dalam proses komunikasi, bahwa para pelaku komunikasi tidak hanya saling memengaruhi, mereka juga terpengaruh dengan konteks cara mereka berinteraksi. Persamaan ketiga, komunikasi merupakan sebuah simbolik, konsep ini menyatakan bahwa simbol-simbol tersebut terbentuk melalui pengalaman dan system dari simbol lainnya.

Menurut Onong dalam komunikasi berdasarkan ruang lingkup ilmu komunikasi dapat di tinjau dari komponen, bentuk, sifat, metode, teknik, model, bidang dan system komunikasi. Komponen komunikasi terdiri dari lima komponen yakni komunikator (communicator), pesan (message), media (media), komunikan (communicant), efek (effect). Proses Komunikasi : a. Komunikasi secara primer, b. Komunikasi secara sekunder, di tinjau dari bentuk komunikasi : 1. Komunikasi personal (personal communication) yang terdiri dari: a. komunikasi intra personal (intrapersonal communication. b. komunikasi antar personal (interpersonal communication). 2. Komunikasi kelompok (group communication): a. komunikasi kelompok kecil (small group communication, meliputi ceramah (lecture), diskusi panel (panel discussion), symposium (symposium), forum, seminar, curahsaran (brainstorming), dan lain-lain. b. komunikasi kelompok besar (large group communication / public speaking), komunikasi massa terdiri dari : 1. Pers, 2. Radio, 3. Televisi, 4. Film, dan lain-lain, Komunikasi medio : 1. Surat, 2. Telepon, 3. Pamflet, 4. 
Poster, 5. Spanduk dan lain-lain. Sifat Komunikasi : 1. Tatap muka (face-face), 2. Bermedia (mediate), 3. Verbal (velball) lisan (oral), 4. Tulisan/cetak (written/printed, 5. Nonverbal (nonverbal): a.kial/isyarat badaniah (gestural), b.bergambar (pictorial). Metode komunikasi terdiri dari : 1. Jurnalistik (journalism);a. jurnalistik cetak (printed journalism),b. jurnalistik elektronik (electronic journalism); 1. Jurnalistik radio, 2.jurnalistik televisi, 2. Hubungan masyarakat (public relation), 3. Periklanan, 4. Propaganda, 5.perang Urat saraf, 6.penerangan. Teknik komunikasi terdiri dari empat: 1. Komunikasi informative (informativecommunication), 2. Komunikasi persuasif (persuasive communication), 3.Komunikasi instruktif (instructive/coercive communication),4.Hubungan manusiawi (human relation), Tujuan komunikasi: a. perubahan sikap (attitude change), b. perubahan pendapat (opinion change), c. perubahan perilaku (behavior change), d.perubahan social (social change). Fungsi komunikasi : a. menyampaikan informasi (to inform), b. mendidik (to educate), c. menghibur (to entertain), d. mempengaruhi (to influence). Model komunikasi : a. komunikasi satu tahap (one step flow communication), b. komunikasi dua tahap (two step flow communication).c. komunikasi multitahap (multistep flow communication). Bidang komunikasi : a.komunikasi social (social communication), b. komunikasi manajemen/organisasional (management/organizational communication). c.komunikasi perusahaan (business communication), d. komunikasi politik (political communication),e. komunikasi internasional, f.komunikasi antar budaya.

Kegiatan pengabdian pada SDIT dan Taman Kanak Islam Terpadu (TKIT) Ar-Rahman I Nagan Raya terletak di Lorong Cot Ganti Desa Simpang Peut Kecamatan Kuala Kabupaten Nagan Raya berdiri sejak tahun 2011. Jumlah lulusan TKIT 210 anak. Sekarang ini sebanyak 92, terdiri dari 54 murid laki-laki dan 38 anak murid perempuan. Dalam proses kegiatan belajar mengajar (KBM) di jalankan oleh sejumlah Guru sebanyak delapan orang dan satu orang kepala sekolah. Kesembilannya terdiri dari Eliza, S.Hum. selaku kepala sekolah, beserta dewan guru yang terdiri dari Sandi Herawati, A.MK, Rahmawati, A.Ma, Nursawida, S.Pd. I, Siti Aisyah, S. KM, Nurmayani, Era Diana,S. KM, Yulia Citra dan Anita serta Eka Yuni Kartika. Kelas A anak didik berjumlah 40 orang dan kelas B berjumlah 41 orang anak didik.

Permalasahan dari pengabdian masyarakat ini adalah bagaimana meningkatkan pengetahuan, pemahaman tentang ilmu komunikasi terutama public speaking, komunikasi pendidikan dalam mentransfer ilmu kepada anaka didik melalui komunikasi efektif di TKIT dan SDIT Ar-Rahman I Nagan Raya.

\section{METODE}

Metode pelaksanaan kegiatan pengabdian masyarakat ini berbentuk pelatihan dan pendampingan, yang pelaksanaannya meliputi perencanaan program komunikasi khususnya dalam melakukan pembelajaran di sekolah serta program evaluasi metode dan teknik komunikasi dalam pembelajaran.

Pada tahap persiapan Tim pengabdian ini melakukan beberapa kegiatan, diantaranya koordinasi dengan pihak peserta melalui penyabaran undangan, pihak guru SDIT dan SDIT yang menjadi sasaran pengabdian. Langkah berikutnya ialah persiapan pembuatan modul pelatihan Penguatan Komunikasi Pembelajaran Bagi Guru TKIT dan SDIT Ar-Rahman I Simpang Peut Kabupaten Nagan Raya, dengan rincian materi sebagai berikut.

Kegiatan-kegiatan atau aktivitas komunikasi pembelajaran masing-masing tahapan adalah Manajemen dan Perencanaan komunikasi, implementasi program komunikasi pembelajaran, bagi guru SDIT dan TKIT Ar-Rahman. Pelatihan ini menyajikan ilmu dan praktek komunikasi dilingkungan sekolah, bagaimana tata cara interaksi dan berkomunikasi antara guru, kepala sekolah, tenaga administrasi sekolah, murid serta orang tua wali murid.

Modul yang digunakan dalam pelatihan berupa modul digita yang dapat diunduh pada https://drive.google.com/file/d/1 hrlqCRSa MpjERo31qm2g02kIkvsCHfS/view?usp=sharing

\section{HASIL DAN PEMBAHASAN}

Pelatihan penguatan komunikasi, dilaksanakan di Ruang Kantor TKIT Ar-Rahman I Simpang Peut Nagan Raya. 


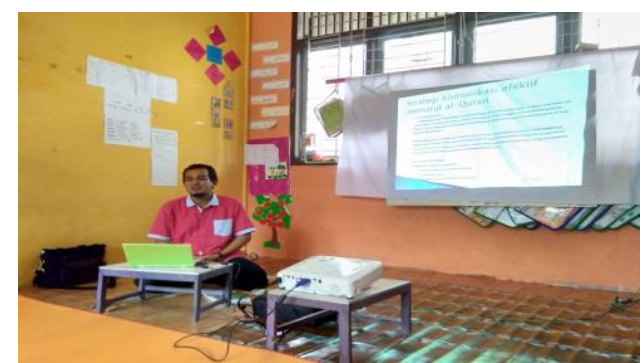

Gambar 1. Photo Pembukaan Kegiatan Pelatihan

Komunikasi guru yang dilakukan di SDIT dan TKIT Ar-Rahman ini sudah terlaksana dengan baik. Hal ini terlihat dari kerjasama guru dan peran memperhatikan cara-cara guru memberikan informasi kepada anak saat pembelajaran. Guru tidak mendominasi pembicaraan tetapi memberikan stimulus kepada anak agar aktif juga untuk memberikan informasi sehingga komunikasi menjadi interaktif.

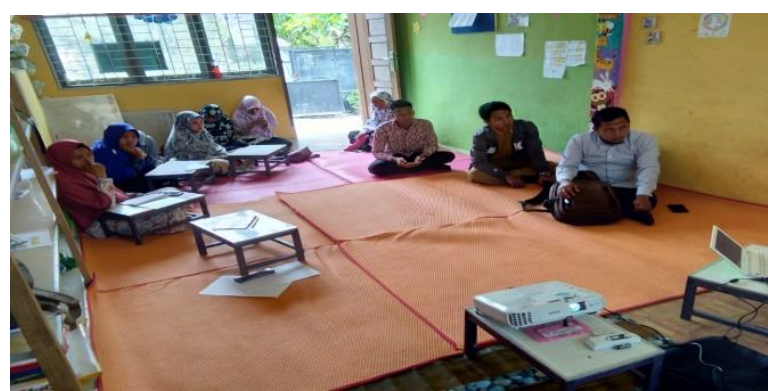

Gambar 2. Photo Keberlangsungan Kegiatan Pelatihan

Untuk mengukur tingkat pemahamaan hasil pelatihan dengan cara membuat sesi tanya jawab dengan dengan guru-guru yang ikut pelatihan sehingga dapat membedakan pola komunikasi, dapat memahami pengertian komunikasi interpersonal, tips meningkatkan keterampilan komunikasi, juga keterampilan pengelolaan kelas.

Metode komunikasi yang disampaikan dalam pembelajaran yang dilaksaanakan oleh seorang guru disaat mengajar paling tidak mengggunakan dua teknik komunikasi yakni teknik komunikasi informasi ( informative communication), tanpa disadari disaat sedang mengajar sedang menyampaikan informasi kepada anak didik. Diharapkan setelah pelatihan dewan guru dapat meningkatkan kemampuannya dalam mengajar, menghadapi anak didik. Penyajian ini dengan mencontohkan secara langsung yang dibantu oleh anggota yang mejadi tim pelatihan dalam sesi yang telah ditetapkan.

\section{SIMPULAN}

Kegiatan pengabdian berupa pelatihan penguatan komunikasi bagi guru TKIT,SDIT ArRahman I Simpang Peut Nagan Raya yang diselenggarakan oleh Dosen dari Universitas Teuku Umar mampu memberikan kontribusi positif terhadap kemampuan komunikasi pembelajaran bagi Guru TKIT,SDIT Ar-Rahman I Simpang Peut Nagan Raya hal melakukan komukasi dengan peserta didik, dan lingkungan sekolah, sehingga memiliki keahlian komunikasi konkrit yang dapat diplikasikan untuk menunjang capaian pembelajaran serta lulusan.

\section{UCAPAN TERIMA KASIH}

Ucapan terima kasih kepada tim pengabdian, dan kepada pihak sekolah yang memfasilitasi kepada penyaji sehingga kegiatan ini dapat berjalan sesuai dengan harapan.

\section{DAFTAR PUSTAKA}

Aang Ridwan. Filsafat Komunikasi, Bandung: Pustaka Setia, 2003

Ainur Rofieq, Materi Pelatihan Keterampilan Teknik Instruksional, Universitas Muhammadiyah Malang, 2013. 
Ahmad A.S. Paradigma Ilmu Komunikasi dalam Pendidikan Tinggi. Jurnal: ISKI No. 5, Jakarta. 1993.

Anwar Arifin. Ilmu Komunikasi: Sebuah Pengantar Ringkas. Jakarta: Rajawali Press. 1988.

Deddy Mulyana. Nuansa-nuansa Komunikasi; Meneropong Politik dan Budaya Komunikasi Masyarakat Kontemporer. Bandung: Rosda karya, 2001.

Ellis, The Dimension of Proverty dalam Social Indicator Reseacrh. G.F.R. 1984

Ocky Karna Radjasa, Panduan Pelaksanaa Penelitian \& Pengabdian Kepada Masyarakat di Perguruan Tinggi, Edisi XI Tahun 2017.

Onong Uchjana Effendy, Ilmu,Teori dan Filsafat Komunikasi. Bandung: Rosdakarya. 2004.

Tim Penyusun, Buku Panduan Pelaksanaan dan Standar Operasional Prosedur (SOP) Pengabdian Kepada Masyarakat Secara Insidentil, Meulaboh : LPPM \& PM Universits Teuku Umar, 2018

Ujang Saifullah, Kapita Selekta Komunikasi, Pendekatan Budaya dan Agama, Bandung: Simbiosa Rekatama Media, 2013. 